\title{
Economia solidária no desenvolvimento: perspectivas a partir da importância da reciclagem de resíduos sólidos
}

Josiane Dilor Brugnera Ghidorsi ${ }^{1}$ Airton Adelar Mueller ${ }^{2}$ Sérgio Luís Allebrandt ${ }^{3}$

Submissão: 28/07/2021 Aceite: 20/09/2021

\begin{abstract}
Resumo
Objetiva-se com este estudo, apresentar aspectos relevantes das dinâmicas da Economia Solidária (ES) para o desenvolvimento socioeconômico, focado no processo de coleta e tratamento de resíduos sólidos, trazendo a discussão sobre a transformação de resíduos em insumos como soluções importantes para o desenvolvimento, com geração de emprego e renda, educação ambiental e evolução social. A pesquisa está ancorada no enfoque da Teoria Crítica, de abordagem Quantitativa/qualitativa, de natureza descritiva, embasado na revisão de literatura narrativa. Verificou-se que a ES é relevante para o processo de desenvolvimento socioeconômico, no entanto, precisa avançar, visto que apenas $23,07 \%$ dos municípios brasileiros apresentam programas de coleta seletiva.
\end{abstract}

Palavra-chave: Economia Solidária. Resíduos Sólidos. Desenvolvimento. Planejamento Urbano e Regional.

\section{Solidarity economy in development: perspectives from the importance of solid waste recycling}

\begin{abstract}
The aim of this study, to present the relevant aspects of Solidary Economy (SE) dynamics for the socioeconomic development, focused on the process of collect and treatment of solid residues, bringing up the discussion concerning the transformation of residues into inputs as important solutions for the development, with job and income generation, environment education and social evolution. The research is based in the Critic Theory scope, essentially construct of Quantitative/qualitative approach and from descriptive nature, based on the narrative literature revision. It was verified that the SE is relevant to the process of socioeconomic development, however, it needs to go forward, since it was noticed that only 23,07\% of the brazilian municipalities present selective collect programs.
\end{abstract}

Keywords: Solidary Economy. Solid Residues. Development. Regional and Urban Planning.

\section{Introdução}

O presente estudo consiste em compreender como a economia solidária pode se constituir em alternativa aos problemas dos resíduos sólidos, que geram impactos

\footnotetext{
${ }^{1}$ Doutoranda em Desenvolvimento Regional (PPGDR-UNIJUÍ). Professora do Centro Universitário UNIFACVEST. https://orcid.org/0000-0003-4959-9272 E-mail: josibrugnera@yahoo.com.br

2 Doutorado em Sociologia (Freie Universität Berlin, Alemanha). Professor no Programa de Pós-Graduação em Desenvolvimento Regional da Universidade Regional do Noroeste do Estado do Rio Grande do Sul (PPGDR-UNIJUI). https://orcid.org/0000-0001-6270-5856 E-mail: airton.mueller@unijui.edu.br

${ }^{3}$ Doutorado em Desenvolvimento Regional (UNISC). Professor e coordenador do Programa de Pós-Graduação em Desenvolvimento Regional da Universidade Regional do Noroeste do Estado do Rio Grande do Sul (PPGDR-UNIJUí). https://orcid.org/0000-0002-2590-6226 E-mail: allebr@unijui.edu.br
}

${ }^{4}$ Doutoranda em Desenvolvimento Regional (PPGDR-UNIJUÍ). Bolsista Prosuc/CAPES. https://orcid.org/0000-0002$\underline{7255-3793}$ E-mail: taciana.ribas@sou.unijui.edu.br 
socioeconômicos e ambientais no desenvolvimento, seja na dimensão local, regional ou territorial, haja visto que um dos grandes problemas atuais na gestão pública, está relacionado à precariedade do saneamento básico, causado pelo aumento de geração de resíduos sólidos, acarretados pelo rápido crescimento das cidades, e a maioria dos gestores públicos não estavam preparados para esta demanda.

Essa discussão vem de longa data, e sabe-se que o saneamento básico enquanto serviço público, vem sendo discutido desde meados do século XIX, pois foi esse o século das primeiras medidas sanitárias, criadas para tentar reduzir o surto de cólera e epidemias que se iniciaram na Ásia e Europa (SANTOS, 1994).

De acordo com Cunha (2018), no Brasil há uma estimativa de que bilhões de pessoas não têm acesso aos serviços de saneamento básico (água potável; coleta, transporte, tratamento e disposição final de esgoto e resíduos sólidos), cenário este que deixa o país com uma lacuna enorme na solução destes problemas, pois há uma ineficiência na elaboração e implementação de políticas públicas nesta área.

No Brasil, a população cresceu 0,8\%, e aumentou entre 2014 e 2015, em 1,7\% na geração de resíduos sólidos, repercutindo na retração de 3,8\% na atividade econômica medida pelo Produto Interno Bruto - PIB (p. 57). Este contexto, deixou o país em uma situação de negligência devido ao descaso do setor público, onde originou-se mais de 1.140 "lixões" a céu aberto, espalhados por todo o âmbito nacional (MARCHI, SILVA, 2018).

Com estas demandas crescendo e os problemas aumentando, se percebeu ser necessário que se tomassem medidas urgentes para sanar tais questões, para que não houvesse um colapso, já a caminho, em todo o território nacional, agravando ainda mais os danos ao meio ambiente, à saúde, ao coletivo.

$\mathrm{Na}$ tentativa de se trabalhar estas lacunas, foram implementadas a Lei Nacional de Saneamento Básico - LNSB e a Política Nacional de Resíduos Sólidos - PNRS, e em apoio a estas, o Plano Estadual de Resíduos Sólidos - PERS, e o Plano Municipal de Gestão Integrada de Resíduos Sólidos - PMGIRS. Não é objetivo principal deste trabalho, trazer um aprofundamento das Leis, mas de forma reduzida, apresentaremos um pouco dos principais elementos destas legislações/planos (Quadro 1).

Sobre a PNRS, cabe salientar que veio, também, para contribuir na quebra de um tabu, em que a nomenclatura "lixo", vinha arraigada de uma conotação de "algo sem valor econômico", passando então, a tratar o "lixo" como resíduos sólidos, dando a ele, não apenas uma valorização econômica, mas como algo de suma relevância nos campos ambiental e social. 
Quadro 1 - Leis e Planos que fundamentam/regulam o saneamento básico no Brasil

\begin{tabular}{|c|c|}
\hline LEIS/PLANOS & DISPOSIÇÕES \\
\hline $\begin{array}{l}\text { Lei Nacional de Saneamento Básico - LNSB, } \\
\text { № } 11.445 \text { de } 05 / 01 / 2007 \text {. } \\
\text { - Substituiu as Leis nos } 6.766 \text {, de } 19 \text { de de- } \\
\text { zembro de } 1979,8.666 \text {, de } 21 \text { de junho de } \\
\text { 1993, e } 8.987 \text {, de } 13 \text { de fevereiro de } 1995 \text {; e } \\
\text { revoga a Lei no } 6.528 \text {, de } 11 \text { de maio de } 1978 \text {. }\end{array}$ & $\begin{array}{l}\text { - Foi considerado o marco legal do saneamento básico. } \\
\text { - Regulamentada pelo Decreto Federal no } 7.217 \text { de } 21 / 06 / 2010 \text {. } \\
\text { - Estabelece diretrizes nacionais para política federal de sanea- } \\
\text { mento básico, colocando este serviço como um conjunto de ser- } \\
\text { viços, infraestruturas e instalações operacionais de abasteci- } \\
\text { mento de água potável; esgotamento sanitário; limpeza urbana e } \\
\text { manejo dos resíduos sólidos; e, drenagem e manejo de das águas } \\
\text { pluviais, limpeza e fiscalização preventiva das redes urbanas. }\end{array}$ \\
\hline $\begin{array}{l}\text { Política Nacional de Resíduos Sólidos - PNRS, } \\
\text { Lei № } 12.305 \text { de 02/08/2010 } \\
\text { - Integra a Política Nacional do Meio Ambi- } \\
\text { ente (PNMM); articula-se com a Política Na- } \\
\text { cional de Educação Ambiental (PNEA) e com } \\
\text { a Política Federal de Saneamento Básico } \\
\text { (PFSB) e com a Lei de Consórcios Públicos. }\end{array}$ & $\begin{array}{l}\text { - Dispõe sobre seus princípios, objetivos e instrumentos, diretrizes } \\
\text { relativas à gestão integrada e ao gerenciamento de resíduos sóli- } \\
\text { dos, incluídos os perigosos, às responsabilidades dos geradores e } \\
\text { do poder público e aos instrumentos econômicos aplicáveis. } \\
\text { - A PNRS define uma ordem de prioridade para a gestão e o geren- } \\
\text { ciamento de resíduos sólidos: não geração, redução, reutilização, } \\
\text { reciclagem, tratamento dos resíduos sólidos e, por fim, disponibi- } \\
\text { lização final ambientalmente adequada dos rejeitos. } \\
\text { - Se aplica às pessoas físicas e/ou jurídicas, de direito público ou } \\
\text { privado, responsáveis diretos ou não, pela geração dos resíduos } \\
\text { sólidos. }\end{array}$ \\
\hline $\begin{array}{l}\text { Plano Estadual de Resíduos Sólidos - PERS } \\
\text { - Instrumento da Política Nacional de Resí- } \\
\text { duos Sólidos - PNRS criado com base na Lei } \\
\text { Federal } 12.305 / 2010 .\end{array}$ & $\begin{array}{l}\text { - Consente aos órgãos técnicos do Estado, empreendedores e ci- } \\
\text { dadãos, estarem a par do cenário atual e a planejar ações objeti- } \\
\text { vando atender as demandas de curto, médio e longo prazo, para } \\
\text { uma gestão satisfatória dos resíduos sólidos produzidos no Es- } \\
\text { tado. } \\
\text { - Devem ser programados visando prazo indeterminado, com } \\
\text { abrangência em toda a dimensão de seu território, com execução } \\
\text { de } 20 \text { anos, e revisões periódicas a cada } 4 \text {. } \\
\text { - Possibilita ao Estado a elaboração de planos microrregionais de } \\
\text { resíduos sólidos, e de projetos específicos focados nas regiões me- } \\
\text { tropolitanas ou aglomerações urbanas. } \\
\text { - Apoiar os planos municipais de gestão integrada e de gerencia- } \\
\text { mento dos geradores de resíduos - públicos ou privados. }\end{array}$ \\
\hline $\begin{array}{l}\text { Plano Municipal de Gestão Integrada de Re- } \\
\text { síduos Sólidos - PMGIRS } \\
\text { - De acordo com a Política Nacional de resí- } \\
\text { duos Sólidos (PNRS) - Lei Federal no } \\
12.305 / 2010 \text { - a gestão integrada de resí- } \\
\text { duos sólidos consiste em um "conjunto de } \\
\text { ações voltadas para a busca de soluções para } \\
\text { os resíduos sólidos, de forma a considerar as } \\
\text { dimensões política, econômica, ambiental, } \\
\text { cultural e social, com controle social e sob a } \\
\text { premissa do desenvolvimento sustentável" }\end{array}$ & $\begin{array}{l}\text { - O PMGIRS deve estar estabelecido no Plano de Saneamento Bá- } \\
\text { sico do Município, incorporando-se aos planos de água, esgoto e } \\
\text { de drenagem urbana. } \\
\text { - Possui a mesma validade dos planos estaduais. } \\
\text { - É requisito fundamental para acesso a recursos da União, ou por } \\
\text { ela controlados, destinados a empreendimentos e serviços relaci- } \\
\text { onados à limpeza urbana e ao manejo de resíduos sólidos. }\end{array}$ \\
\hline
\end{tabular}

Fonte: elaboração própria, extraído do site planalto.gov.br/Brasil, 2010 e de MARCHI, SILVA, 2018.

De Freitas et al (2019, p. 225), faz uma reflexão sobre a nomenclatura e a conjuntura ao qual o termo lixo é empregado, onde para ele "[...] quem julga que algo não lhe serve mais é o próprio gerador do resíduo. [...] não cabe afirmar que lixo é "coisa imprestável" já que pode ser facilmente e muito bem reutilizado, pelo seu usuário".

Sobre resíduos sólidos, de acordo com Cunha (2018), estes são “materiais, substâncias, objetos ou bens descartados resultantes das atividades humanas em sociedade", cujo destino 
final, deve ser dado da forma correta onde poderá haver o aproveitamento dos mesmos, gerando emprego e renda, bem como, trabalhar a inclusão cidadã, a partir da educação ambiental, tendo como elemento primordial o reaproveitamento e a transformação dos resíduos para o processo de reciclagem.

Esta afirmação vem ao encontro com o que está disposto na Política Nacional de Resíduos Sólidos (PNRS) que traz o rejeito como sendo:

[...] resíduos sólidos que, depois de esgotadas todas as possibilidades de tratamento e recuperação por processos tecnológicos disponíveis e economicamente viáveis, não apresentem outra possibilidade que não a disposição final ambientalmente adequada (BRASIL, 2010).

Neste caminho, alia-se a isto, a Economia Solidária - ES, que vem como uma ferramenta, apresentada como um ideário para um "novo modelo de desenvolvimento sustentável, includente e solidário" (DA SILVA \& DA SILVA, 2008), uma vez que, os resultados econômicos, sociais, políticos e culturais, beneficiam a todos os envolvidos.

Assim, vislumbra-se como um dos parâmetros ou alternativas para a ES, qual seja a transformação de resíduos recicláveis descartados para o fim de gerar fonte de renda, empregabilidade direta e indireta, e ainda, como meio de cooperação, por meio do associativismo com o meio ambiente e o desenvolvimento social, humano e econômico.

Nesse contexto, quando citamos a ES e a cooperação em busca do desenvolvimento, todavia, devemos trazer a lume temporalmente a evolução no contexto mundial, em especial as transformações ocorridas nas últimas três décadas, como a redefinição das funções do Estado, tendo em vista o pós-guerra, a globalização e os efeitos do neoliberalismo.

Deste modo, observa-se que as respectivas variações ou reposicionamentos dos agentes da sociedade civil e da necessidade de novos mecanismos reguladores são necessárias para readequar o controle das externalidades produzidas pelo sistema capitalista. As alterações do sistema e o papel das organizações que atuam no campo social e tecnológico, que visam o capital, estiveram mais voltadas aos interesses de caráter positivista e empresarial. Em razão de que, as normativas e regulamentações sempre bloquearam a promoção e o incentivo do cooperativismo local e social.

Nesta esteira, percebe-se quão ineficiente o Estado tornou-se nas últimas décadas, seja no fomento e aplicabilidade das políticas públicas em regulamentação do mercado, quanto na livre concorrência e iniciativa. Importante reforçar, que as deficiências citadas anteriormente 
correspondem aos princípios da economicidade, ordem econômica, tudo em busca da equidade, conforme proposto no texto do artigo 170 da Carta Magna de 1988.

Em trilha oposta à tendência, inseriu-se como modelo de economia solidária cidadã a proposta de reciclagem de resíduos em espaços associativos. A proposta de reciclagem vislumbra um segmento social de material reciclável que integra o cenário urbano, em busca da sustentabilidade. No Brasil, há muito anos, este modelo aplica-se em espaços espalhados nas pequenas e grandes cidades.

Em linhas mestras, o objetivo geral do trabalho é apresentar esse modelo, ou a perspectiva enquanto parâmetros de enfrentamento da inclusão/exclusão econômica e social. Ainda busca-se apresentar alternativas às restrições que lhes são infringidas pela dinâmica do mercado de trabalho, com estratégias de ações coletivas em busca de cidadania em trabalho associativo, empreendedor e dinâmico no âmbito local, reduzindo os impactos ambientais e tendo como pressuposto a reciclagem.

Para melhor compreensão deste estudo, o mesmo, além desta introdução, apresenta os apontamentos metodológicos que trazem os procedimentos de coleta de dados e da pesquisa; o referencial teórico com abordagem sobre os aspectos da Economia Solidária e do Associativismo, avançando para o papel da reciclagem enquanto fonte de renda e de desenvolvimento sustentável; indo para os resultados e discussões, que discorrem sobre os resultados acerca das dinâmicas da coleta de resíduos sólidos, delineando com os aspectos da Economia Solidária, em que a análise principal se baseou em dados coletados nos estudos do Sistema Nacional de Informações sobre Saneamento - SNIS e Ministério do Meio ambiente - MMA; finalizando-se com as considerações finais com o entendimento dos autores, onde se buscou fazer uma discussão com o referencial teórico, encerrando-se com as referências bibliográficas presentes neste artigo.

\section{Metodologia}

O âmbito da investigação no presente estudo, atrela-se a análise empírica, a partir de estatísticas de coletas e reciclagem dos municípios do Brasil, enquanto agentes transformadores no processo de educação ambiental, gerenciamento de descartes conforme dispõe as políticas públicas. Em especial, a formação de renda e inclusão dos menos assistidos no modelo capitalista vigente, numa perspectiva de economia solidária. 
Neste caminho, este estudo está ancorado no enfoque da teoria crítica, pois esta enfatiza o papel da ciência na transformação da sociedade, uma vez que procura averiguar a realidade dos grupos e instituições, associando as ações humanas com aspectos culturais, sociais e políticos, no intuito de compreender as redes de poder - como são geradas, conduzidas e modificadas (ALVES-MAZZOTTI \& GEWANDSZNAJDER, 2004; ALLEBRANDT, 2010).

A presente investigação se enquadra ainda como uma pesquisa bibliográfica de revisão de literatura narrativa, uma vez que não se utilizou de protocolo pré-definido.

\begin{abstract}
A revisão de literatura narrativa, não exige um protocolo rígido para sua confecção, uma vez que este método, apresenta uma temática mais aberta, onde a busca das fontes não é pré-definida e proporciona aos investigadores selecionar os artigos arbitrariamente, fornecendo aos autores informações sujeitas a viés de seleção, com grande interferência da percepção subjetiva (UNESP, 2015).
\end{abstract}

Corroborando, Gil (2010, p. 29), aponta que a pesquisa bibliográfica é elaborada com base em material já publicado. Tradicionalmente, esta modalidade inclui material impresso, como livros, revistas, jornais, teses, dissertações e anais de eventos científicos".

Este foi o caminho utilizado pelos investigadores, onde se valeram de textos escritos por autores que estão alinhados com o objeto de estudo, bem como, com os estudos aplicados no Programa de Pós-Graduação em Desenvolvimento Regional - PPGDR/Unijuí.

Tem-se no presente estudo, uma pesquisa de natureza descritiva cujo propósito consiste em entender e descrever características de um determinado modelo ou fenômeno (GIL, 2002), e permite que os pesquisadores se aprofundem na busca de informações acerca do objeto explorado, relatando os acontecimentos e fenômenos de uma determinada realidade (TRIVIÑOS, 1987).

Quanto a abordagem, pode-se afirmar que é híbrida enquanto elementos de investigação, pois ao mesmo tempo que se tem resultados baseados em dados quantitativos extraídos do SNIS e do MMA por meio da análise de modelos sustentáveis, manejo dos descartes e na viabilização da reciclagem como fonte de renda e inclusão cidadã, ainda se tem um olhar qualitativo onde não há uma preocupação com uma representatividade numérica.

Por esta pesquisa também classificada como descritiva, pois se objetiva encontrar e relacionar as variáveis existentes em uma determinada realidade, é que se justifica a abordagem quantitativa, uma vez que se procura descobrir e classificar a relação entre variáveis, os quais propõem descobrir as características de um fenômeno possui elementos que quantificam a coleta de dados e o tratamento das informações, onde os investigadores se apropriam de dados estatísticos (RICHARDSON, 1999). Deste modo, se entende que os resultados obtidos não são 
passíveis de manipulação/distorção ou com margem de erros, dando mais confiabilidade (DIEHL, 2004). Assim, se constata que a pesquisa quantitativa oferece aos pesquisadores, um método que pode ser mensurado em escala numérica.

No que concerne à pesquisa qualitativa, de acordo com Minayo (2001), esse método de amostragem é interessante, pois possibilita abranger a totalidade do problema investigado em suas múltiplas dimensões e está fundamentada na compreensão de um determinado grupo social ou organização. O intuito principal está em explicar o porquê de determinadas situações, enfatizando o que melhor convêm a ser feito, sem a necessidade de mensurar valores, uma vez que as trocas simbólicas não são submetidas à prova dos fatos, pois os dados analisados são nãométricos e se valem de diferentes abordagens.

Ainda, para esta pesquisa, utilizou-se da análise documental. Esta técnica possibilita aos pesquisadores, a partir da análise do documento, relatar de forma mais objetiva as informações contidas no mesmo (BARDIN,1997). Neste estudo analisou-se a Lei Nacional de Saneamento Básico - LNSB e a Política Nacional de Resíduos Sólidos - PNRS, bem como documentos/relatórios disponíveis no SNIS e MMA.

\section{Referencial Teórico}

Este tópico tem por finalidade trazer a contextualização acerca das temáticas sobre Economia Solidária e Associativismo; e, Desenvolvimento e Coleta Seletiva, no intuito de enfatizar a importância desta discussão, tanto nos meios acadêmicos como na sociedade, a fim de disseminar uma consciência ambiental, ao mesmo tempo, mostrar o quanto as pessoas/indivíduos, são atores sociais importantes neste processo, estando diretamente envolvidos ou não com a coleta, uma vez que somos todos "produtores" destes resíduos.

\subsection{Aspectos da economia solidária (ES) e do associativismo}

No tocante à Economia Solidária, doravante descrita como ES, objeto em pauta, o projeto de associação para a reciclagem dos resíduos descartados seria uma alternativa de renda e inclusão na temática cidadã.

Cumpre afirmar o entendimento pontual do idealizador Singer (2002), que chamou o projeto de "cooperativismo revolucionário". Assim, verifica-se que a economia solidária surge 
como uma forma de proposta às classes populares, gerando emprego e renda, com proposta diferenciada, além de estimular a economia local.

Neste viés, a economia solidária se apresenta como uma forte alternativa, por se tratar de um modelo econômico que surge categoricamente, em que as comunidades buscam suas particularidades e organização inclusiva no desenvolvimento econômico. Assim, a participação coletiva faz com que os integrantes criem laços de amizade e integração, em virtude da ampla participação social.

Em especial, no Brasil a economia solidária foi solidificando-se e fomentando suas matrizes e paradigmas, tendo ocorrido a sua primeira conceituação somente nos anos 90, com a obra: "Economia de Solidariedade e Organização Popular" do teórico Luis Razeto, que discorre com vistas ao tema, pontuando-o como:

[...] uma formação teórica de nível científico, elaborado a partir e para dar conta de produtos significativos de experiências econômicas [...], que compartilham alguns traços constitutivos e essenciais de solidariedade, mutualismo, cooperação e autogestões comunitárias, que definem uma racionalidade especial, diferente de outras racionalidades econômicas (RAZETO, 1993, p. 40).

Conforme supracitado, nota-se que esta visão no Brasil se tornou fator relevante e decisivo para libertar, em parte, as amarras do capitalismo. Da mesma forma, enquanto perspectiva de inclusão alternativa para a sociedade na busca de renda direta e indireta mostrase como opção relevante.

Por sua vez, em linhas verossimilhantes, no viés econômico e integrativo Singer (1998, apud Singer 2002), aponta que o desemprego estrutural, reflexo da globalização, não aumenta necessariamente o número de desempregados, mas ao contrário, intensifica a deterioração do mercado de trabalho através da precarização e das terceirizações.

Mediante estes diagnósticos acima elencados, nos reportamos à economia solidária e ao associativismo, que nos remete ao posicionamento de Singer (2002), o qual dispõe que a economia solidária se originou na Inglaterra durante a Segunda Revolução Industrial.

De acordo com o autor, a princípio, as cooperativas inglesas rejeitavam o lucro, sendo o cooperativismo um modo de produção alternativo ao capitalismo, contribuindo para o amplo desenvolvimento do comércio em países como Inglaterra, França e Suíça. Entretanto, o cooperativismo de consumo perdeu a disputa para o grande capital, pois esse, ofereceu preços atrativos e atendeu aos consumos homogeneizados, em que pese, ainda, existir espaço para demandas específicas e para aquelas atividades que possam ser realizadas em pequena escala. 
Nesse aspecto, no Brasil, o cooperativismo iniciou-se em meados do século XX, incorporado por imigrantes europeus. Existiam cooperativas de consumo nas cidades, que faliram em razão do crescimento do varejo e das cooperativas agrícolas, que se tornaram na maioria, tornaram-se, em regra, empresas capitalistas (SINGER, 2002).

Em conformidade com o pensamento do teórico Singer (2002), considera-se o cooperativismo um modo de produção, o qual todos os seus membros são iguais e cooperam entre si. Na empresa solidária, a remuneração dos sócios ocorre com o recebimento de valores variáveis de acordo com a receita obtida.

Neste modelo, as decisões são tomadas de forma coletiva, com a efetiva participação dos sócios durante assembleia, havendo assim, a autogestão. O destino do lucro nas cooperativas é decidido através de assembleias. Comumente é investido uma parte em um fundo indivisível e o restante divide-se entre os sócios.

Dessa forma, o trabalho torna-se rentável, vantajoso, o qual agrega-se a mão de obra informal, inserindo as vítimas da exclusão social, que são um dos grandes problemas na sociedade. Resta claro, conforme considerações de Singer (2002) apresentadas para a reflexão, que a exclusão se relaciona por vezes devido ao mercado de trabalho não possuir meios para absorver toda a mão de obra existente, evidenciando assim, um dos cenários visíveis e cruéis na contemporaneidade.

O viés da ES e do cooperativismo pode ser utilizado como mecanismo de reinserção ao mercado de trabalho, com a consequente formação de renda direta para os, então, excluídos e, sobretudo, o rearranjo da economia local como reflexo. Importante destacar ainda, a Economia Solidária surgiu como resposta, por parte de diferentes grupos sociais, às contradições do sistema capitalista e às imperfeições das relações de mercado, pois uma parcela da população excluída do mercado de trabalho formal busca sua sobrevivência coletivamente (SINGER, 2002).

Neste contexto, se percebe que a ES passa a ter mais relevância, auferindo mais espaços no Brasil, colocando as associações, cooperativas ou atividades solidárias como protagonistas neste cenário. Essas organizações se moldaram inicialmente como entidade informais ou grupos comunitários de produção, cooperativa e/ou pequenas empresas, e tinham a frente trabalhadores que se encontravam sem possibilidades de sustento e/ou motivados por suas ideologias (GAIGER, 2004).

Essas associações que atuam no campo da Economia Solidária se caracterizam por terem a autogestão e socialização dos meios de produção e distribuição como principais elementos, onde não há divisão entre capital e trabalho, sendo eles mesmos, detentores do capital 
(FERREIRA, 2005). Para Oliveira (2005), o setor da Economia Solidária nasceu no espaço intermediário entre Estado, mercado e setor informal, para cumprir um papel social, econômico e político, onde abarcou as famílias, comunidades e redes que exercem um papel importante na sociedade.

A ES é considerada um passo concreto, indispensável para dar credibilidade e gerar intensa adesão social aos propósitos de uma nova arquitetura mundial, prova necessária para evitar apenas o oferecimento de uma ideologia mistificadora, de alternativas inaplicáveis (GAIGER, 2004, p. 799).

O que proporciona força para a economia solidária é a capacidade dos atores sociais, em coordenarem estas organizações diante das alternâncias no interior do processo produtivo, evidenciando o papel da governança na economia política local (POCHMANN, 2004). Ainda, o autor sugere que esta dinâmica provavelmente esteja inserida na dimensão macroeconômica nacional, a qual desempenha um importante papel nas perspectivas de avanço ou retrocesso do desenvolvimento local ou regional.

Assim, são múltiplas as iniciativas que caracterizam a economia solidária, tais como as cooperativas com seus coletivos de trabalhadores organizados com base na democracia, nas tomadas de decisões e organizadas em diferentes setores da economia. Além de outras formas de associativismo ou grupos informais de organização socioprodutiva, existe um verdadeiro pluralismo organizacional, com suas variáveis estruturantes.

Essas iniciativas colocam o cidadão como protagonista no cenário do desenvolvimento, por meio das organizações do setor da Economia solidária. Isso exige uma transformação política e social, onde esses sujeitos se tornam os principais atores sociais, e que possam atuar junto ao gestor social, discutindo sobre as ações que visem o desenvolvimento. Ademais, nas palavras do teórico Brandão (2008, p. 154):

O desenvolvimento enquanto processo multifacetado de intensa transformação estrutural resulta de variadas e complexas interações sociais que buscam o alargamento do horizonte de possibilidades de determinada sociedade". [...] isso implica na "construção social e política de trajetórias sustentadas e duradouras e deve ser dotada de durabilidade orgânica, sendo permanentemente inclusiva de parcelas crescentes das populações marginalizadas dos frutos do progresso técnico, endogeneizadora de centros de decisão e ter sustentabilidade ambiental.

Por assim dizer, o desenvolvimento ocorre por meio dos agentes locais, sociais, que a partir das dinâmicas da ES, passam a implementar e fomentar este setor na cadeia de produção, recuperação e reciclagem de resíduos sólidos e ainda, colaboram no aspecto de inclusão e desenvolvimento sustentável. Essa ideia é trabalhada por Da Silva \& Da Silva $(2008$, p. 02) em que ancorados em Gomes et al (2007), sugerem que 
o desenvolvimento sustentável se dá por meio de associações alicerçadas nos elementos que fundamentam a Economia Solidária, uma vez que este cenário pode ser um grande propulsor na melhoria da qualidade de vida de todos os atores sociais envolvidos, e essa melhoria reflete nas gerações presentes e/ou futuras, acarretando no desenvolvimento harmônico e sustentável.

Contudo, constata-se que é por meio dos atores sociais envolvidos nestes processos e dinâmicas da ES, que é possível que ocorra o diálogo sobre o desenvolvimento. Essa participação social não pode ser colocada de lado, pois esses sujeitos são parte do constructo da promoção social, da democracia participativa, na construção de ambientes equilibrados e produtivos e na associação com preceitos fundamentais da ES (GOMES et al., 2007). Deste modo, para melhor enfatizar estas dinâmicas da ES e do associativismo, o tópico a seguir vai tratar sobre a questão do desenvolvimento e coleta seletiva, e a reciclagem como meio para o desenvolvimento sustentável e socioeconômico.

3.2 Desenvolvimento e Coleta seletiva: a reciclagem de resíduos como alternativa de desenvolvimento sustentável e fonte de geração de emprego e renda

A Constituição Brasileira de 1988 promoveu a perspectiva do desenvolvimento sustentável, quando estabeleceu no artigo 170, que a liberdade de iniciativa é um dos fundamentos da ordem econômica constitucional, desde que as pessoas cumpram seus princípios, um dos quais, a defesa do meio ambiente. Isto é, a liberdade de empresa não pode ser desconectada da obrigação de proteção ambiental, mas sim sujeita a ela e é uma de suas condições. No que se refere à reciclagem e seu importante papel na ordem econômica, para o meio ambiente e para o desenvolvimento sustentável, é importante destacar o caráter da educação ambiental e das políticas públicas.

Neste sentido, o Supremo Tribunal Federal identificou a "limitação da liberdade de iniciativa" com base no princípio da proteção do ambiente: a atividade econômica não pode ser exercida sem harmonia com os princípios de eficácia da proteção ambiental. Ou seja, a segurança do meio ambiente não pode ser comprometida pelos interesses corporativos ou se tornarem dependentes de natureza puramente econômica das corporações.

Acreditava-se que a sustentabilidade estaria amplamente envolvida com o meio ambiente. Ocorre que teóricos entendem que a sustentabilidade necessita apoiar-se em vários pontos, dos quais se destacam três: o social, o econômico e o ambiental. Considerando que a existência da sustentabilidade depende dessa relação socioeconômica e ambiental, ela pode ser 
vista como um grande sujeito e discutida de diferentes maneiras. Sachs (2002), por exemplo, utiliza, definindo oito tipos de sustentabilidade: (social, econômica, ecológica, espacial, territorial, cultural, política nacional e política internacional) para apresentar as dimensões do que denomina ecodesenvolvimento.

Logo, o quesito sustentabilidade baseia-se num conceito de solidariedade, como um vínculo intergeracional no direito ao meio ambiente e permite uma nova concepção de responsabilidade ética que vai além da esfera de proximidade dos sujeitos envolvidos. Portanto, a sustentabilidade necessita de planejamento, acompanhamento e avaliação dos resultados. Observa-se, assim, que a sustentabilidade é condizente com o crescimento econômico fundamentado na justiça social e eficiência no uso dos recursos naturais (LOZANO, 2012).

A partir desse aspecto, a análise sobre a reciclagem como consequência da transformação da matéria-prima para a elaboração de novos produtos, e o acréscimo na renda familiar de coletores e cooperativas de reciclagem, são ações e elementos que contribuem para coibir os impactos ambientais, estimulando a preservação em favor do presente e das futuras gerações; um verdadeiro direito intergeracional, conforme assinala o teórico Carvalho (2013).

Nessa direção, tendo como pressuposto a ideia de reciclagem e transformação de resíduos, levamos em conta a questão de gestão e desenvolvimento local, com percepções de suma relevância, tais como: ganhos ambientais e ganhos culturais. Ambos os ganhos resultam em politização e consciência em favor da educação dos atores sociais. O que, por sua vez, insere estes sujeitos de direitos e obrigações na órbita social e nos benefícios das esferas públicas na geração de empregabilidade, renda, e ainda, no resgate social inclusivo.

Quanto aos encaminhamentos das esferas públicas, destacamos o relevante papel da coleta seletiva, incentivo à reciclagem, participação em cooperativas e dos demais atores locais/sociais, de forma regionalizada nos municípios para demonstrar as dimensões virtuosas da reciclagem. Tornando assim, instrumento indispensável para a cadeia de produção e para o desenvolvimento estratégico e de políticas econômicas solidárias.

\section{Resultados e Discussão}

No Brasil, a imagem do trabalho dos catadores ou coletores de resíduos está integrada há muitos anos, em especial no cenário urbano. A atuação do coletor, por diversas vezes, se dá sob condições que comprometem sua integridade física, em muitos casos de forma autônoma e isolada. No entanto, o movimento coletivo, por meio de cooperativas e associações têm 
apresentado aumento expressivo, devido a implementação da PNRS (Política Nacional de Resíduos Sólidos).

A PNRS foi um marco para a gestão dos resíduos sólidos no país, por estabelecer os princípios, objetivos, instrumentos e dispõe sobre as diretrizes referentes à gestão e ao gerenciamento desses resíduos, inclusive os perigosos, às responsabilidades dos geradores e do poder público e aos instrumentos econômicos aplicáveis (BRASIL, 2010).

Em razão de que, dispõe em suas alíneas sobre o que precisa ser feito ou conduzido no processo de manejo dos resíduos sólidos no país. Para além disso, cria instrumentos importantes para a redução e geração dos resíduos, aumentando consequentemente, a reciclagem, a reutilização e destinação ambiental adequada. Uma dessas mudanças decorrentes da PNRS é a logística reversa, que segundo o art. 3o, inciso XII, da PNRS (BRASIL, 2010) entende-se por:

[...] um instrumento de desenvolvimento econômico e social caracterizado por um conjunto de ações, procedimentos e meios destinados a viabilizar a coleta e a restituição dos resíduos sólidos ao setor empresarial, para reaproveitamento, em seu ciclo ou em outros ciclos produtivos, ou outra destinação final ambientalmente adequada (BRASIL, 2010).

Outra alteração depois da PNRS, não menos importante é o estabelecimento da responsabilidade compartilhada pelo ciclo de vida dos produtos, que segundo o art. $3 \circ$, inciso XVIII da PNRS trata-se de um grupo de medidas individuais e ordenadas por parte dos fabricantes, importadores, distribuidores e comerciantes, dos consumidores e dos titulares dos serviços públicos de limpeza urbana e de manejo dos resíduos sólidos, no sentido de diminuir os resíduos sólidos e rejeitos gerados, bem como para a redução das implicações causadas à saúde humana e à qualidade ambiental decorrentes do ciclo de vida dos produtos (BRASIL, 2010).

Os instrumentos legais que partem da PNRS possibilitam, por exemplo, o surgimento de novas vertentes que vem para facilitar o processo de manejo dos resíduos. Sendo que, a reutilização dos resíduos (aproveitamento do resíduo sem que ocorra uma transformação biológica, física ou físico-química), como política tem colaborado, tanto para a ampliação do número de cooperativas de catadores, quanto para o crescimento de catadores individuais, que veem essa atividade como meio de se obter trabalho e renda, diante a falta de perspectivas melhores.

Logo, o aumento dos resíduos sólidos e a grande demanda de trabalho no setor (incluindo formação de cooperativas e de catadores individuais), são reflexos da expansão da produção inteligente e do aumento do consumo em massa, gerados pelo fenômeno da Quarta ou Nova 
Revolução Industrial, a chamada Industria 4.0. Fenômeno mundial faz gerar uma gama maior de insumos para a produção e consequentemente, ocorre um excessivo descarte em lixões em virtude do crescente consumo de produtos nos centros urbanos por parte da sociedade, como também, das indústrias.

Importante observar que, a indústria 4.0 tem otimizado a produção de bens e serviços, por meio das fabricas inteligentes, em que cada vez se produz mais, com melhor qualidade e agilidade. Por outro lado, utilizam-se, ao mesmo tempo, um grande volume de combustíveis como, petróleo, gás natural, carvão mineral, para este feito, sempre em busca da satisfação das necessidades da população, da indústria e do comércio. Trata-se de energias não renováveis e de extração recorrente, que, ao serem queimadas, elevam a emissão de gases poluentes, interferindo veemente nas mudanças climáticas, que ocasionam excessivo calor ou frio, alagamentos, terremotos, secas, dentre outros problemas ambientais.

Diante dessa forte demanda energética, faz surgir como solução a pratica da Logística Reversa, que é a transformação de resíduos sólidos em matéria-prima energética. Política que ganha mais espaço e solidez no sistema econômico contemporâneo, de modo que, se consolida como uma alternativa eficiente e eficaz para a solução dos problemas, diminuindo a extração de recursos naturais e dos problemas ambientais gerados pelo aumento dos resíduos sólidos.

De acordo com o Anuário da Reciclagem (AR, 2018, p. 8), Logística Reversa (LR)

[...] é o conjunto de ações para que o resíduo pós-consumo retorne para a cadeia produtiva, substituindo matéria-prima virgem. Esse fluxo inclui várias etapas, primeiro a coleta dos resíduos, posteriormente, sua triagem e destinação adequada (reutilização, reciclagem ou compostagem). Com isso, a LR busca, principalmente, diminuir os resíduos depositados nos aterros sanitários ou lixões, e reduzir a extração de matériasprimas.

Ações relevantemente sociais, econômicas e ambientais, tendo em vista de que "com intenso avanço da urbanização e industrialização da sociedade nas últimas décadas, houve também grande crescimento da geração de resíduos" (AR, 2018, p. 7). E, portanto, a necessidade urgente de ações para gerenciar esses resíduos e o uso indiscriminado de recursos naturais, como no caso a implementação da PNRS, que também, contribui significativamente para o aumento de cooperativas, que vão realizar o processo de coleta seletiva lá na ponta da cadeia de resíduos. Sendo assim, o descarte adequado e o reaproveitamento dos resíduos sólidos, além de servirem de combustíveis e diminuir a extração de recursos naturais pela indústria, consequentemente, contribuem para a qualidade na saúde da população e do meio ambiente e o desenvolvimento sustentável. 
Diante do exposto, é salutar frisar, que os catadores de resíduos sólidos recicláveis, como também, as cooperativas de catadores, tem significativa importância nesse cenário, sobretudo porque são os agentes responsáveis pela coleta, triagem e destinação desses materiais, para que tenham destinação adequada, especialmente para a reciclagem. Confirmando estas afirmativas, a Pesquisa Ciclosoft 2018, assinalou que, 1227 municípios do país, que corresponde a 22\% do total, dispõem de programas de coleta seletiva. E cerca de 35 milhões de cidadãos tem acesso a programas municipais de coleta seletiva, observando-se que os programas mais satisfatórios ocorrem quando há uma consonância de modelos de coleta seletiva (CEMPRE, 2018).

Os dados da pesquisa ainda, revelam que a coleta de resíduos "porta a porta" corresponde $80 \%$, os pontos de entrega voluntária (PEVs) equivalem a $45 \%$ e as cooperativas representam $64 \%$ destas, isto é, as cooperativas ou organizações coletivas de coletas seletivas são a maioria dos agentes recicláveis. De acordo ainda com a pesquisa, considerando que, os municípios podem ter mais de um administrador de coleta seletiva (agentes executores), 39\% dos municípios pesquisados realizam a sua própria coleta; em $36 \%$ as empresas particulares são contratadas para fazê-la; e, 50\% destes apoiam ou mantém cooperativas de catadores (CEMPRE, 2018).

O apoio às cooperativas está baseado em: maquinários, galpões de triagem, ajudas de custos com água e energia elétrica, caminhões (incluindo combustível), capacitações e investimento em divulgação e educação ambiental. Na pesquisa 2018 ficou evidenciado o crescimento da participação dos catadores organizados em associações e/ou cooperativas (CEMPRE, 2018).

Com isso, é possível afirmar que metade dos municípios pesquisados incentivam as cooperativas, sendo que estas são responsáveis por mais da metade $(64 \%)$ da coleta de resíduos em municípios que possuem esse tipo de serviço, gerando consequentemente valor econômico e social para os munícipes.

Complementando ainda, os dados de 2018, a pesquisa realizada pelo Cempre em 2020, apresenta significativas mudanças, além de desenvolvimento do setor, isso porque, em 2020, 1.269 municípios do Brasil já têm acesso ao serviço de coleta seletiva, um adendo de 42 municípios em dois anos. A pesquisa traz, também, informações e indicadores relacionados à gestão pública da coleta seletiva municipal de 341 municípios, que correspondem a cerca de 35\% da população brasileira. Bem como, observa que, tanto a zona rural, quanto a urbana, o método de coleta porta a porta é o mais utilizado, atendendo respectivamente $72,96 \%$ e $90,47 \%$ da população envolvida. 
Em relação ao agente executor da coleta seletiva, a maior parte do serviço é efetivado por empresas licitadas (50,85\%). O estudo também, identificou 549 organizações de catadores, presentes em 24 unidades federativas. Mais de 95\% destas organizações são classificadas principalmente como associações ou cooperativas de catadores. As entidades que responderam à pesquisa, empregaram juntas quase 15 mil pessoas, e reciclaram 350 mil toneladas em 2019.

As unidades de triagem consultadas possuem em média 27 catadores e comercializam em média 26,3 t/mês. Quanto à forma de remuneração dos serviços, a pesquisa verifica que em torno de $73,77 \%$ dos catadores têm algum tipo de vínculo com o poder público municipal e 56,47\% são apoiados por programas de logística reversa. Em relação à remuneração, 86,7\% dos catadores recebem entre 0,5 e 2 salários-mínimos. A pesquisa também revela um aumento de $186 \%$ na coleta seletiva desde a publicação da PNRS, que tem como objetivo a redução da quantidade de resíduos para aterros e lixões (TETRA PAK, 2021).

Ou seja, tendo por base esse conjunto de dados, é possível afirmar que todo esse conjunto de ações, como, aumento de cooperativas e catadores, aumento da destinação correta de resíduos, valor agregado do produto reciclado, logística reversa, dentre outros aspectos, incidem positivamente, na diminuição de resíduos, favorece ao meio ambiente, gera a sustentabilidade, favorece o desenvolvimento econômico e social da população, e acima de tudo são iniciativas que surgem em perspectiva da aplicação da lei na prática, no caso da PNRS.

O Gráfico 1, demonstra o crescimento de número de municípios que possuem coletas seletivas, sendo que, em 1994 eram cerca de 81 municípios indo para 1269 no ano de 2020.

Gráfico 1 - Evolução dos números de municípios com coleta seletiva no Brasil, de 1994 a 2020

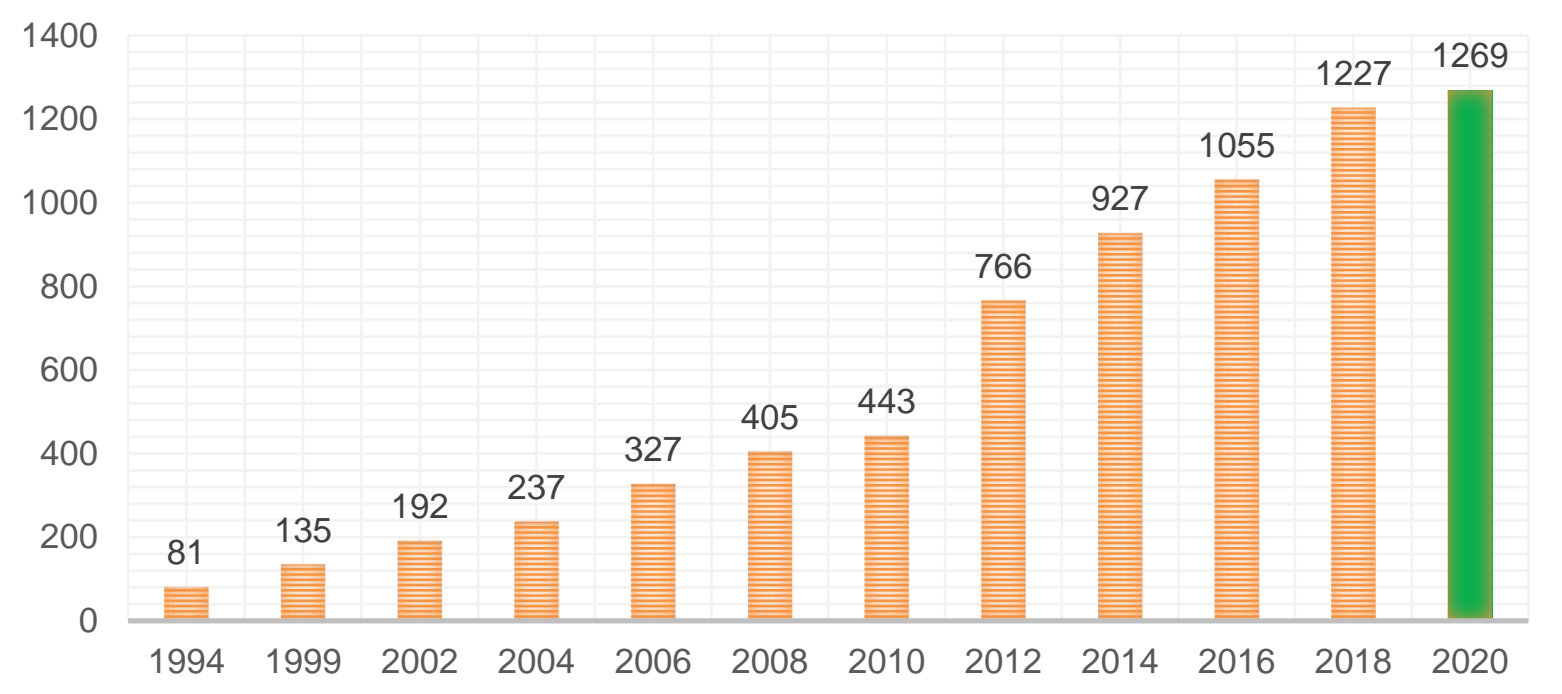

Fonte: Elaborado a partir de dados das pesquisas da Cempre, 2018 e 2020. 
De acordo com os dados apresentados pela Cempre 2018 e 2020, levando em consideração que o Brasil possui atualmente cerca de 5570 municípios (IBGE, 2020), somente $22,78 \%$ destes municípios, possuem algum tipo de coleta seletiva, ficando de fora desse contingente $77,22 \%$ de municípios. Na sequência, observa-se o número de entidades associativas de resíduos recicláveis, por região, de 2011 a 2018, sendo que nas regiões Sul e Sudeste estão acomodadas um maior número de associações de reciclagem (Gráfico 2).

Gráfico 2 - Número de entidades associativas de catadores, de 2011 a 2018

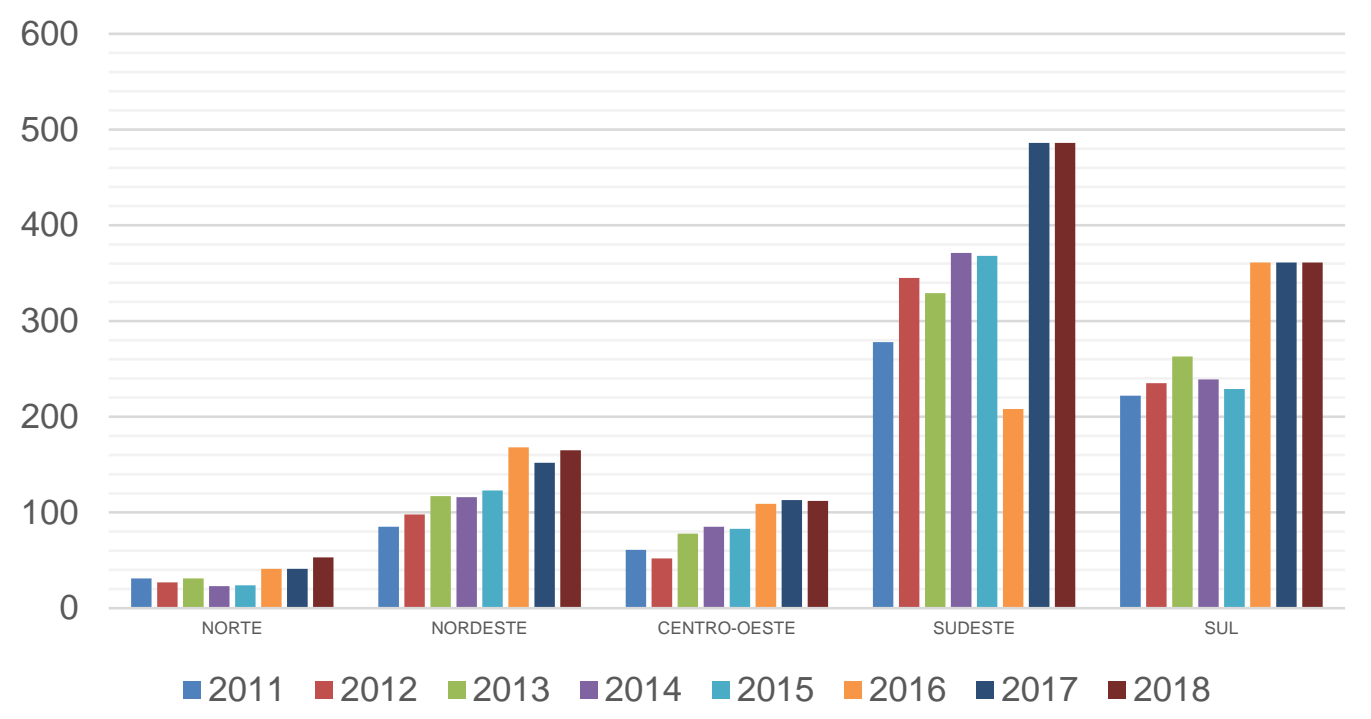

Fonte: Elaborado pelo autor, conforme a SNIS-RS, 2012 a 2019 (ano-base 2011 a 2018).

O número de catadores em 2011 a 2018 segue sempre em ascendência desde 2011, porém, com um pequeno declive de 7 pontos em 2015, conforme o demonstrado no gráfico 3.

Gráfico 3 - Número de organizações de catadores 2011 a 2018, no Brasil

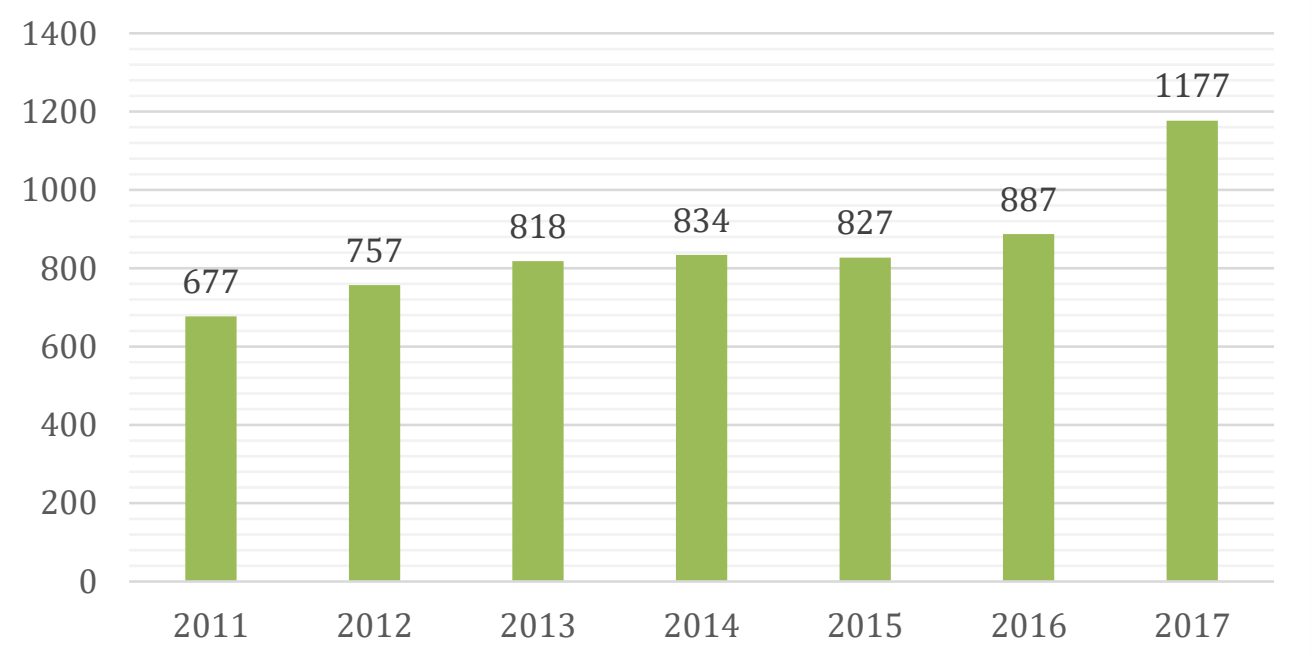

Fonte: Elaborado pelo autor, conforme a SNIS-RS, 2012 a 2019 (ano-base 2011 a 2018). 
Considerando os dados apresentados, é possível afirmar que em 6 anos, de 2011 a 2017, desde a promulgação da PNRS de 2010, houve um acréscimo de 500 entidades associativas de catadores. Em seguida, na tabela 1, podem ser visualizados os dados relativos ao número de entidades associativas em 2018, 2019 e 2020.

Tabela 1 - Número de entidades associativas de catadores de 2018 a 2020

\begin{tabular}{ll}
\hline № de entidades associativas de catadores & Ano \\
\hline 1200 & 2018 \\
1480 & 2019 \\
1829 & 2020
\end{tabular}

Fonte: Autor, com base nos dados da pesquisa Tetra Pak (2021).

O conjunto de dados esboçados na tabela 1, permite averiguar que no período de três anos (2018, 2019 e 2020) houve um acréscimo de 629 entidades associativas de catadores, crescimento considerável de entidades, mais que o somado em sete anos, avaliando o demonstrado anteriormente (Gráfico 3). Contudo, considerando que de acordo com dados do Banco Mundial o Brasil é o 4o produtor, no mundo na produção de plástico (PÍRES, 2021), o número de cooperativas para dar conta de tudo isso, teria que ser superior.

Por meio de análise dos números e perspectivas da realidade, minuciosamente apontadas até o momento, é possível frisar ainda que o desenvolvimento do setor de reciclagem e a ampliação de cooperativas associadas a economia solidária pode ter relação direta com os Planos de coleta e gestão de coleta elaborado e implementados pelas administrações públicas desde a criação da PNRS em 2010.

Em relação aos Planos e a gestão de coleta pode-se observar estes são uma obrigação jurídica estabelecida na PNRS de 2010, por parte do poder público municipal, sendo que em suas metas de coleta seletiva devem constar um plano de gestão integrada de resíduos sólidos. 0 Plano de Gestão Integrada de Resíduos consiste em

[...] um conjunto de ações exercidas, direta ou indiretamente, nas etapas de coleta, transporte, transbordo, tratamento e destinação final ambientalmente adequada dos resíduos sólidos e disposição final ambientalmente adequada dos rejeitos, de acordo com plano municipal de gestão integrada de resíduos sólidos ou com plano de gerenciamento de resíduos sólidos (BRASIL, 2010).

Entende-se por coleta seletiva a "coleta de resíduos sólidos previamente segregados conforme sua constituição ou composição" (BRASIL, 2010). A reciclagem é um processo industrial 
que converte o resíduo descartado (matéria-prima) em produto semelhante ao inicial ou algum outro tipo de produto. Para tanto, as associações de catadores de materiais recicláveis, também chamados de empreendimento coletivos de resíduos recicláveis que têm grande importância na cadeia produtiva da reciclagem.

O passo seguinte a apresentar é o Sistema Nacional de Informações sobre Saneamento, porque, nessa esteira, além do olhar econômico é importante reforçar o aspecto legal e eficaz disposto no Sistema da Política Nacional de Resíduos Sólidos. Em seus arts. 1으 e 2으, lei no Lei no 12.305/2010 dispõe a respeito do campo de aplicação e seu objeto, já o artigo 3o possui definições de extrema importância para a adoção de políticas corretas para a preservação do meio ambiente, com destaque ao controle e a destinação dos resíduos sólidos produzidos diariamente no país.

O sistema que deve ser utilizado pelos padrões desta lei se encontra em específico no artigo 3, capítulo II, da Lei no 12.305/2010, enquanto ferramenta ao desenvolvimento. Face a essas perspectivas, a gestão dos Estados e Municípios de forma autônoma, a fim de auxiliar na implementação de projetos ambientais de cunho sustentável e assegurando a eficácia do desenvolvimento dos mesmos está destacada no artigo 18 da Lei no 12.305/10, em igual teor:

Art. 18. A elaboração de plano municipal de gestão integrada de resíduos sólidos, nos termos previstos por esta Lei, é condição para o Distrito Federal e os Municípios terem acesso a recursos da União, ou por ela controlados, destinados a empreendimentos e serviços relacionados à limpeza urbana e ao manejo de resíduos sólidos, ou para serem beneficiados por incentivos ou financiamentos de entidades federais de crédito ou fomento para tal finalidade.

Entende-se, portanto, que a lei é de suma importância para o ambiente, visando o seu cuidado com resíduos que podem apresentar problemáticas graves e preocupantes, tanto ao contexto ambiental quanto para a saúde pública, devido à ausência de gerenciamento e manuseio irregular. Nessa mesma linha a Lei de Diretrizes Orçamentárias aprovada em 2009, trouxe em seu artigo 34 a possibilidade de transferência de recursos, a título de auxílios

[...] voltadas diretamente às atividades de coleta e processamento de material reciclável, desde que constituídas sob a forma de associações ou cooperativas integradas por pessoas em situação de risco social, na forma prevista em regulamento do Poder Executivo, cabendo ao órgão concedente aprovar as condições para a aplicação dos recursos (IPEA, 2011, p. 58). 
Avanço importante que estimula a organização de entidades cooperadas no setor da reciclagem, entretanto, apesar da legislação favorecer o desenvolvimento de entidades associativas como estas, é relevante também, o poder público propor políticas públicas destinadas a educação ambiental, a coleta seletiva, a reciclagem e transformação dos resíduos sólidos, que são cada vez mais produzidos pela população brasileira, como ainda, instituir mecanismos econômicos para subsidiar a geração de trabalho e renda e a inclusão social dos catadores de resíduos sólidos e suas famílias, garantido os direitos fundamentais constituídos.

Destaca-se que uma das mais relevantes discussões mundiais na atualidade, o papel da reciclagem pelo seu caráter minimizador dos impactos ao meio ambiente e aos direitos intergeracionais. Por conseguinte, os efeitos positivos destas dinâmicas na atuação da gestão social, economia solidária, aos agentes locais, é importante mensurar algumas dimensões de suma relevância.

Uma dessa dimensões, entre outras, aparece a educação e a conscientização do meio ambiente, tendo em vista o reconhecimento de que a crise ambiental é um dos aspectos da crise do modelo ocidental, esta terá que enfrentar um grande desafio. Este desafio envolve considerar a possibilidade de assumir a obrigação de ter um comportamento sustentável, bem como, inclui como sujeitos do direito ao meio ambiente aqueles que ainda não nasceram e os que irão nascer.

Outra dimensão se refere aos aspectos legais norteadores, como a Carta Magna de 1988 em seu disposto legal artigo 225, Lei Federal no 6.938/91 que tutela a Política Nacional do Meio Ambiente à Política Nacional de Resíduos Sólidos. Uma robusta legislação, como a Lei no 12.305/10 e a Lei dos Crimes Ambientais no 9.605/98, que deveria transcender ao caso concreto de forma efetiva e com equidade.

Quanto ao papel do Estado na aplicabilidade e fiscalização dos princípios constitucionais de desenvolvimento sustentável, bem como da tutela jurídica ambiental. Isto porque a Constituição Federal de 1988 também conceitua Meio Ambiente, em seu artigo 225, aduzindo que todos possuem o direito ao meio ambiente, de forma com que ele seja ecologicamente equilibrado, para bem de uso comum à toda a população e se fazendo essencial à uma correta qualidade de vida. Desta forma, impõe-se à população e ao Poder Público a obrigação de defendê-lo e preservá-lo para as presentes e futuras gerações (BRASIL, 1988).

Nessa perspectiva, a criação e implementação de políticas públicas eficientes e eficazes destinadas ao descarte adequado dos resíduos e a sua reciclagem, no âmbito local e regional, permitem a geração de trabalho e renda, a inclusão social e cidadania dos catadores e suas famílias. Isto acontece quando há o incentivo à organização de cooperativas e de entidades 
associativas, o que tende a contribuir para o desenvolvimento econômico dos municípios e pode acabar com os "lixões", locais que contaminam o ambiente e acabam prejudicando a saúde da população. Sendo assim, pode ser dito que a reciclagem é um modelo sustentável e paliativo para minimizar o impacto humano no meio ambiente e, por conseguinte, ao impacto socioeconômico a partir dos arranjos e dinâmicas da economia solidária local.

\section{Considerações finais}

Constatou-se pelo presente estudo, através do modelo de economia solidária e associativismo, que estas variáveis podem minimizar os impactos socioeconômicos e socioambientais que afetam os municípios brasileiros, conforme diagnósticos já demonstrados. Nesse sentido, conforme quantificado no presente estudo, em análises de coleta e reciclagem, observou-se que os dados das regionalizações dos municípios no Brasil, no decorrer dos anos de 2014 a 2017, evoluíram de acordo com o passar dos anos, contudo numa proporção pequena ainda. Verificou-se que, no Brasil, esse crescimento corresponde a $23,1 \%$ e que apenas 1.320 municípios têm programas de coleta seletiva, onde apenas $2 \%$ desse lixo é separado para reciclagem.

Nesse contexto, observou-se que no ano de 2015 as informações colhidas de relatórios divulgados pelo Ministério do Meio Ambiente detectaram um aumento considerável de aproximadamente $19 \%$ dos municípios que declararam possuir Planos de Gestão Integrada de Resíduos Sólidos, com potencial para gerar receita sustentável para o município. Em 2020, o Ministério divulgou dados sobre a gestão de resíduos sólidos no Brasil, todos referente ao ano de 2017. Registrando que no respectivo relatório, observou-se que pouco mais da metade dos municípios brasileiros, aproximadamente $54,8 \%$, possuíam Plano Integrado de Resíduos.

Quanto à iniciativa de reciclagem, segundo dados do CEMPRE (2018), 44\% desses municípios diagnosticados mantém cooperativas de catadores como agentes executores da coleta de lixo municipal. E ainda, que $67 \%$ dos casos são de empresas privadas contratadas para executarem a coleta, sendo que há um grande número, ainda não mensurado, de catadores informais.

Nesse processo que versa desenvolvimento do local ao regional, a partir das articulações das políticas públicas na busca paliativa para além do olhar econômico é relevante destacar a Política Nacional de Resíduos Sólidos, lei no 12.305/2010 artigos 1a e 2a dispõe a respeito do campo de aplicação e seu objeto. Já o artigo 3o possui definições de extrema importância para a 
adoção de políticas corretas para a preservação do meio ambiente, com destaque para o controle e a destinação dos resíduos sólidos produzidos diariamente no país. Em especial, há uma análise a partir do âmbito local na qual se constatou um baixo grau de eficiência dos municípios no controle do acúmulo de descartes sem destinação adequada. Como resultado, há no Brasil um significativo montante de municípios que, de forma geral, banalizam esse importante processo que implica em prejuízos ao homem e ao meio ambiente.

Nesse sentido, reforça-se o entendimento, o debate do localismo sobre o desenvolvimento, seja empreendedorismo, economia solidária e popular, capital social, enfim, nesse contexto, que "o local pode tudo", dependendo de sua vontade de auto impulso (CASTELLS, BORJA, 1997).

O crescimento da economia solidária é notório, porque, apesar das dificuldades, os resultados que se apresentam são muito significativos, com maior evidência nos benefícios para a população do campo e da cidade, na geração de trabalho e renda e na promoção do desenvolvimento local e na preservação ambiental proporcionada por esta. Isso porque a economia solidária é uma área com uma gama de oportunidades e desafios. Em sua prática, sempre se sobressai a unidade de produção e a solidariedade, sem deixar de lado os trabalhadores que dela precisam.

Quanto à questão do aumento no número de cooperativas, é importante ressaltar que após a promulgação da PNRS em 2010, que estabeleceu os objetivos, os instrumentos e as diretrizes de gestão integrada e gerenciamento de resíduos sólidos no país, houve um aumento significativo dessas cooperativas. Esse aumento de cooperativas e da coleta seletiva nos municípios se deve muito a própria política que prevê o fim dos denominados "lixões". Esta política acabou incentivando investimentos nos municípios e por outro lado, estimulando os catadores a se organizar enquanto cooperados, por meio de organizações coletivas ou pela economia solidária.

Em razão de a reciclagem ser uma atividade econômica e social engajada em garantir a qualidade de vida e um novo tipo de consumo, o sustentável, que além de contribuir para um novo modo de vida dos que desta participam, contribui para a proteção do meio ambiente, com base na territorialidade e no desenvolvimento local. Isto pode acontecer porque o desenvolvimento é resultado das relações humanas e de pessoas que, dependendo das suas escolhas, desejos, vontades, decisões e desempenho, podem ou não contribuir para o desenvolvimento local e, até mesmo, global. 
ALLEBRANDT, Sérgio Luís. Cidadania e gestão do processo de desenvolvimento: um estudo sobre a atuação dos conselhos regionais e municipais de desenvolvimento do Rio Grande do Sul, de 1990 a 2009. Santa Cruz do Sul. 2010. 312f. Tese (Doutorado em Desenvolvimento Regional) -Universidade de Santa Cruz do Sul - UNISC.

ALVES-MAZZOTTI, Alda Judith; GEWANDSZNAJDER, Fernando. O Método nas Ciências Naturais e Sociais: pesquisa quantitativa e qualitativa. São Paulo: Pioneira Thomson Learning, 2004.

AR. Anuário de Reciclagem (AR): Relatório de Atuação da Associação Nacional dos Catadores e Catadoras de Materiais Recicláveis (ANCAT) 2017-2018. Disponível: https://cempre.org.br/wpcontent/uploads/2020/11/2-Anu\%C3\%A1rio-da-Reciclagem.pdf. Acesso em: 04 jun 2021.

BARDIN, Lawrence. Análise de conteúdo. Lisboa: Edições 70; 1997. 176 p.

BRASIL. Leis e Decretos. Constituição da República Federativa do Brasil de 1988. Disponível em: http://www.planalto.gov.br. Acesso em: 10/ago/ 2019.

BRASIL. Lei no 12.305/10 Institui a Política Nacional de Resíduos Sólidos; altera a Lei no 9.605, de 12 de fevereiro de 1998. Disponível em: http://www.planalto.gov.br. Acesso em: 10/ago/2019.

BRASIL. Lei no 11.445, de 05 de janeiro de 2007. Disponível em: http://www.planalto.gov.br. Acesso em: 20/11/2020.

BRASIL, Ministério do Meio Ambiente. Dados estatísticos sobre reciclagem no Brasil. Disponível em: www.mma.gov. Acesso em 10 de agosto de 2019.

BRASIL, Ministério do meio ambiente. Legislação. Disponível em: http://www.mma.gov.br. Acesso em: 16/jun/2019.

BRANDÃO, Carlos. Desenvolvimento, territórios e escalas espaciais: levar na devida conta as contribuições da economia política e da geografia crítica para construir a abordagem interdisciplinar. In: RIBEIRO, Maria Teresa Franco; MILANI, Carlos R. S. Compreendendo a complexidade socioespacial contemporânea: o território como categoria de diálogo interdisciplinar. Salvador: Editora da UFBA, p. 150-185. 2008.

CARVALHO, Délton Winter de. Dano ambiental futuro: a responsabilização civil pelo risco ambiental. 2. ed. rev., atual e ampl. - Porto Alegre: Livraria do Advogado Editora, 2013.

CASTELLS, Manuel; BORJA, Jordi. As cidades como atores políticos. Novos Estudos CEBRAP, $n$. 45, jul. 1997, p. 152-166.

CAVALCANTI, L. L.; NOGUEIRA, M. S. Futurismo, Inovação e Logística 4.0: desafios e oportunidades. VII Congresso Brasileiro de Engenharia de Produção, da Associação Paranaense de Engenharia de Produção (APREPRO). Ponta Grossa - PR. 2017. 10p.

CEMPRE. Compromisso empresarial com a reciclagem. Disponível em: http://cempre.org.br/. Acessado em 10 de agosto de 2019.

CEMPRE. Compromisso Empresarial para Reciclagem: Pesquisa Ciclosoft 2018, radiografando a coleta seletiva. Disponível em:https://cempre.org.br/wp-content/uploads/2020/08/PesquisaCiclosoft-2018.pdf. Acesso em 04 jun 2021. 
CRESWELL, John W. Projeto de pesquisa - métodos qualitativo, quantitativo e misto: Métodos Qualitativo, 2008.

CULTI, Maria Nezilda. Economia Solidária: Geração de Renda, Mitos e Dilemas. Unitrabalho. 2006. Acesso 09/11/2020. Disponível em:

http://unitrabalho.org.br/paginas/noticias/artigos/pdf/E.Solid\%C3\%A1ria\%20\%20Gera\%C3\% A7\%C3\%A3o\%20de\%20renda,\%20mitos\%20e\% 20dilemas.pdf.

CUNHA, Mateus Almeida. A gestão municipal dos resíduos sólidos: cenários e desafios. In MARCHI, Cristina Maria Dacach Fernandez (Org.). Gestão dos Resíduos Sólidos: conceitos e perspectivas de atuação. 1a ed. Curitiba: Appris, 2018. p. 19-41.

DA SILVA, José Luís Alves; DA SILVA, Sandra Isabel Reis da Silva. A economia solidária como base do desenvolvimento local. E-Cadernos CES [On-line], V. 02, p. 01-15, 2008.

DE FREITAS, Manolo Cleiton Costa et al. Diagnóstico da Gestão de Resíduos Sólidos no Transporte Hidroviário do Município de Breves (Pa). Revbea, São Paulo, V. 14, №1:222-244, 2019.

DIEHL, A. A. Pesquisa em ciências sociais aplicadas: métodos e técnicas. São Paulo: Prentice Hall, 2004.

FERREIRA, Cândido Guerra. A economia popular solidária em Belo Horizonte: um estudo exploratório. Texto de discussão n. 255. Belo Horizonte: UFMG/Cedeplar, 2005.

GAIGER, Luiz Inácio. A economia solidária e o projeto de outra mundialização. Revista de Ciências Sociais. Rio de Janeiro, v. 47, n. 4, 2004, p. 799-834.

GIL, Antônio Carlos. Como elaborar projetos de pesquisa. 4.ed. São Paulo: Atlas, 2002.

GOMES, Fabiana Pereira et al. Economia Solidária e Desenvolvimento Local e Sustentável. Projecto Casa Brasil: MTE, SENAES. 2007.

INSTITUTO DE PESQUISA ECONÔMICA APLICADA (IPEA). Relatório da situação social material reciclável Brasil. Disponível em: www.ipea.gov . Acessado em 10 de agosto de 2019.

INSTITUTO BRASILEIRO DE GEOGRAFIA E ESTATÍTICA (IBGE). Estimativas da população residente no Brasil e unidades da federação com data de referência em 1 de julho de 2020. Disponível em:

$\mathrm{ftp}: / / \mathrm{ftp}$. ibge.gov.br/Estimativas_de_Populacao/Estimativas_2020/estimativa_dou_2020.pdf. Acessado em 18 de junho de 2021

LOZANO, R. Towards better embedding sustainability into companies' systems: an analysis of voluntary corporate initiatives. Journal of Cleaner Production, v.25, n.0, p.14-26, 2012.

MARCHI, Cristina Maria Dacach Fernandez (Org.). Gestão dos Resíduos Sólidos: conceitos e perspectivas de atuação. 1a ed. Curitiba: Appris, 2018. 223p.

MARCHI, Cristina Maria Dacach Fernandez; SILVA, Mayara Luize Rebouças Nascimento. A elaboração dos planos de gerenciamento de resíduos sólidos: apoio à Gestão Pública. In MARCHI, Cristina Maria Dacach Fernandez (Org.). Gestão dos Resíduos Sólidos: conceitos e perspectivas de atuação. 1a ed. Curitiba: Appris, 2018. p. 57-69.

MINAYO, Maria Cecília de Souza (org.). Pesquisa Social. Teoria, método e criatividade. 18o ed. Petrópolis: Vozes, 2001. 
OLIVEIRA, Luciana Vargas Netto. Economia solidária e conjuntura neoliberal: desafios para as políticas públicas no Brasil. Dissertação (Mestrado). Curitiba: Universidade Federal do Paraná, 2005.

POCHMANN, Mário (organizador). Reestruturação produtiva: perspectiva de desenvolvimento local com inclusão social. Petrópolis: Vozes, 2004.

RAZETO, L. Economia de solidariedade e organização popular. In: GADOTTI, M; GUTIERREZ F. (Org). Educação comunitária e economia popular. São Paulo: Cortez, 1993. p.34-58.

RICHARDSON, R. J. Pesquisa social: métodos e técnicas. São Paulo: Atlas, 1999.

SACHS, Ignacy. Estratégias de transição para o século XXI: desenvolvimento e meio ambiente. São Paulo: Nobel, 1993.

SANTOS, Luiz Antonio de Castro. Um Século de Cólera: Itinerário do Medo. Physis - Revista de Saúde Coletiva. V. 4, № 1, p. 79-110, 1994.

SINGER, Paul. Introdução à Economia Solidária. Introdução à Economia.1ạ ed. São Paulo: Editora Fundação Perseu Abramo, 2002.

TETRA PAK. Ciclosoft 2020 aponta crescimento de $\mathbf{1 8 6 \%}$ na coleta seletiva desde a publicação da PNRS: Pesquisa Ciclosoft 2020. Public. 15 mar 2021. Disponível em:

https://www.tetrapak.com/pt-br/about-tetra-pak/news-and-events/newsarchive/ciclosoft2020-aponta-crescimento-na-coleta-seletiva. Acesso em: 05 jun 2021.

TRIVIÑOS, A. N. S. Introdução à pesquisa em ciências sociais: a pesquisa qualitativa em educação. São Paulo: Atlas, 1987.

UNESP. Tipos de Revisão de Literatura. 2015. Disponível em: file:///E:/tipos-de-revisao-deliteratura.pdf. Acessado em 26/07/2020. 